\title{
Occupational exposure to blood and body fluids among primary healthcare workers in Johannesburg health district: High rate of underreporting
}

\begin{tabular}{|c|c|}
\hline \multicolumn{2}{|c|}{$\begin{array}{l}\text { Authors: } \\
\text { Collins C.E. Mbah }{ }^{1} \text { (D) } \\
\text { Zuberu B. Elabor }{ }^{2} \\
\text { Olufemi B. Omole }\end{array}$} \\
\hline \multicolumn{2}{|c|}{$\begin{array}{l}\text { Affiliations: } \\
{ }^{1} \text { Department of Family } \\
\text { Medicine, University of } \\
\text { the Witwatersrand, } \\
\text { Johannesburg, South Africa }\end{array}$} \\
\hline \multicolumn{2}{|c|}{$\begin{array}{l}{ }^{2} \text { Eastern Cape Department } \\
\text { of Health, Aliwal North, } \\
\text { South Africa }\end{array}$} \\
\hline \multicolumn{2}{|c|}{$\begin{array}{l}\text { Corresponding author: } \\
\text { Collins Mbah, } \\
\text { emekambah@yahoo.com }\end{array}$} \\
\hline \multicolumn{2}{|c|}{$\begin{array}{l}\text { Dates: } \\
\text { Received: } 15 \text { Nov. } 2019 \\
\text { Accepted: } 07 \text { Jan. } 2020 \\
\text { Published: } 14 \text { May } 2020\end{array}$} \\
\hline \multicolumn{2}{|c|}{$\begin{array}{l}\text { How to cite this article: } \\
\text { Mbah CCE, Elabor ZB, } \\
\text { Omole OB. Occupational } \\
\text { exposure to blood and body } \\
\text { fluids among primary } \\
\text { healthcare workers in } \\
\text { Johannesburg health district: } \\
\text { High rate of underreporting. } \\
\text { S Afr Fam Pract. 2020;62(1), } \\
\text { a5027. https://doi. } \\
\text { org/10.4102/safp.v62i1.5027 }\end{array}$} \\
\hline \multicolumn{2}{|c|}{$\begin{array}{l}\text { Copyright: } \\
\text { (C) 2020. The Authors. } \\
\text { Licensee: AOSIS. This } \\
\text { is licensed under the } \\
\text { Creative Commons } \\
\text { Attribution License. }\end{array}$} \\
\hline \multicolumn{2}{|l|}{ Read online: } \\
\hline 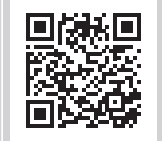 & $\begin{array}{l}\text { Scan this QR } \\
\text { code with your } \\
\text { smart phone or } \\
\text { mobile device } \\
\text { to read online. }\end{array}$ \\
\hline
\end{tabular}

Background: Healthcare workers (HCWs) are at risk of bloodborne infections from sharp instrument injuries and skin and mucous membrane exposures to contaminated blood and body fluids (BBF). While these have clinical and occupational health implications, little is known about BBF exposure and its reporting pattern in South African primary healthcare (PHC). The aim of this study was to determine the rate of BBF exposure, the extent of reporting and the reasons for not reporting among HCWs in PHC facilities in Johannesburg, South Africa.

Methods: In a cross-sectional study involving 444 participants, an 18-item, self-administered questionnaire was used to collect information on socio-demographic characteristics, HCWs' exposures to BBF in the last year, whether the exposure was reported and the reasons for not reporting. Analysis included descriptive statistics and chi-square test.

Results: Most participants were nurses (87.4\%) and female (88.1\%). About a quarter of participants (112) reported having at least one BBF exposure in the last year. Overall, there were 355 exposures, resulting in $0.8 \mathrm{BBF}$ exposure per HCW per year. Of these exposures, $291(82.0 \%)$ were not reported. Common reasons for not reporting include lack of time $(42.72 \%)$, perception that the source patient was at low risk for human immunodeficiency virus (24.7\%) and concerns about confidentiality $(22.5 \%)$. Blood and body fluids exposures involving nurses $(p<0.001)$, sharp instrument $(p<0.001)$ and HCWs aged $<50$ years $(p=0.02)$ were significantly more likely to be reported.

Conclusion: This study found a high rate of underreporting of BBF exposures among HCWs in PHC facilities in Johannesburg, suggesting an urgent need for interventions to improve reporting.

Keywords: blood; body fluids; occupational exposure; healthcare workers; injury reporting; sharps exposure.

\section{Introduction}

Healthcare workers (HCWs) are at risk of many bloodborne infections following injuries with sharp instruments and exposure of mucous membrane and non-intact skin to contaminated blood and body fluids (BBF). The World Health Organization (WHO) has estimated that 3 million HCWs worldwide experience needlestick and sharps injuries every year. ${ }^{1}$ Auta et al. found the pooled global 1-year prevalence estimate of percutaneous injuries among HCWs to be $36.4 \% .^{2}$ In South Africa (SA), the prevalence of percutaneous injuries among HCWs is high with rates as high as $23.35 \%$ reported among HCWs at Witbank Hospital. ${ }^{3}$ Also consistent with international reports, doctors and nurses are by far most affected by these injuries. ${ }^{2}$ Although primarily associated with transmission of hepatitis B virus (HBV), hepatitis $\mathrm{C}$ virus (HCV) and human immunodeficiency virus (HIV), these injuries and exposures may transmit more than 20 bloodborne pathogens (BBP). ${ }^{4}$ As many as $47 \%$ of $\mathrm{HBV}$ and $45 \%$ of $\mathrm{HCV}$ infections in $\mathrm{HCWs}$ in the developing world are attributable to percutaneous occupational exposure. ${ }^{5}$ The prevalence of bloodborne virus (BBV) infection in SA HCWs is estimated to mimic that of the general population: HBV $0.2 \%-16 \%$, HIV $17.9 \%$ and HCV $2.4 \%{ }^{6}$ Traditionally, the prevention of BBF exposures has been based on the hierarchy of controls, which includes hazard elimination, the use of safer devices, administrative controls involving development of policies on training and educating HCWs on how to limit exposure to BBF, and work practice controls. ${ }^{7}$ In many countries (SA included), it has not been possible to implement preventive strategies because of poor supporting estimates of the burden of occupational exposure to BBP. ${ }^{8}$ This has led to the introduction of the concept of evidence-based prevention (EBP). ${ }^{9}$ Evidence-based prevention involves the use of root 
cause analysis, a process for identifying causal factors to use in injury prevention. Such information, including the circumstances of occupational transmission of BBP, helps in targeting and evaluating interventions. Reporting injuries and documenting all BBF exposures also enable the employee to receive appropriate post-exposure management and compensation.

Many of the available occupational BBF exposure statistics use data from officially reported incidents that may not be a true reflection of workplace events. Furthermore, studies both locally and internationally have reported high rates of underreporting of BBF exposures among HCWs, with most of these focusing on HCWs at secondary and tertiary healthcare facilities. ${ }^{10,11,12}$ Although the risk of exposure to $\mathrm{BBF}$ among HCWs at primary healthcare (PHC) facilities can be extrapolated, to some degree, from the literature on HCWs at secondary and tertiary levels, the rates of reporting or/and underreporting of such exposures, and reasons for underreporting may be very different.

Many PHC facilities in SA have fewer than 10 employees/ clinicians, resulting in lack of on-site infection control and employee wellness programmes. Stigma may also be a big factor as the few staff members know each other too well and may not be willing to volunteer personal health information that is required for the reporting of BBF exposure incidents. To this end, little or no data exist on reporting of $\mathrm{BBF}$ exposures by HCWs at PHC facilities in SA despite the peculiarities and challenges faced by workers at this service level. We therefore sought to determine the rate of $\mathrm{BBF}$ exposure and the reasons for underreporting among HCWs in primary care facilities in Johannesburg.

\section{Methods}

This was a cross-sectional study conducted in 15 primary care clinics, one community health centre and one district hospital in Johannesburg district between January 2013 and April 2013. All surveyed facilities had written protocols or guidelines on reporting of accidental occupational exposures to BBFs by HCWs.

The study population included 544 HCWs made up of 56 medical doctors, four dentists and 484 nurses working in the facilities during the study period. Doctors and nurses who were on leave and all allied HCWs were excluded from this study. Although a sample size of 384 was determined adequate, all the $544 \mathrm{HCWs}$ were invited to participate.

An 18-item self-administered questionnaire adapted from the Centers for Disease Control and Prevention design with demonstrated external validity ${ }^{13}$ was used for data collection. This questionnaire collected data on the socio-demographic characteristics of the participants, their exposures to BBF in the preceding 1 year, whether the exposures were reported or not and their reasons for not reporting, if any.
The first author personally distributed the questionnaires to eligible HCWs at each facility following prior telephonic arrangements with the facility managers. Each facility was visited a minimum of two times for distribution and collection of the questionnaires between January and April 2013. Completed questionnaires were dropped off in a sealed box placed at a known location in each facility. Participation in this study was voluntary and completion of the questionnaire implied consent.

Data were analysed with the help of a statistician using Microsoft Excel spreadsheet for cleaning and coding purposes and Epi Info 7 statistical software (Centers for Disease Control and Prevention in Atlanta, Georgia, United States) for analysis. Outcomes of interest included the number of BBF exposures per participants within the past year, the proportion of exposures reported and the reasons for not reporting, if any.

A pilot study was carried out at a commuinty health centre (CHC) in another sub-district outside the study area to determine the feasibility of the main study. Fifteen respondents (5 doctors and 10 nurses) were included in the pilot study. They were subsequently interrogated by the first author following which minor changes were made to the questionnaires to improve clarity. The results of the pilot study were not included in the final analysis.

\section{Ethical considerations}

Ethical approval for the study was granted by the Human Research Ethics Committee (HREC) of the University of the Witwatersrand (Ethics clearance certificate number M121150). Permission was also granted by the Johannesburg metropolitan health district and the City of Johannesburg local government health department.

\section{Results}

A total of 515 questionnaires were distributed (58 doctors and 457 nurses). Of these, 466 were returned ( $90.5 \%$ response rate). Of the 466 returned, 22 were excluded because of incomplete information, leaving 444 questionnaires (56 doctors and 388 nurses) for analysis.

As shown in Table 1, most of the participants were female $(88.1 \%)$, nurses $(87.4 \%)$ and based in the district hospital $(54.7 \%)$. The mean age was 39.8 years with a mean work experience of 11.7 years.

A total of 112 participants (25.2\%) - 27 doctors and 85 nurses - were exposed to BBF in the last year (Table 2). The total number of exposures was 355, resulting in an exposure rate of 0.8 per HCW per year and three exposures per exposed HCW per year (Table 3). Of the 355 exposures, 159 (44.8\%) were caused by sharp and 196 $(55.2 \%)$ by non-sharp objects. An estimated $82 \%$ (291) of the total exposures were not reported to the designated health official. 
Of the 112 HCWs exposed to BBF, 44 (39.3\%) reported at least one exposure and only 23 (20.5\%) reported all incidents. More than $60 \%$ (68) did not report any of the exposures (Table 4).

As shown in Table 5, reasons for not reporting BBF exposures included lack of time $(42.7 \%, n=38)$, perceptions that the source patient was at low risk for $\operatorname{HIV}(24.7 \%, n=22)$ and concerns about confidentiality $(22.5 \%, n=20)$. Table 6 shows that underreporting of BBF exposures was significantly associated with being $>50$ years of age $(p=0.018)$, being a doctor $(p=0.011)$ and having $>20$ years of work experience $(p=0.049)$.

\section{Discussion}

This study found that HCWs in this public PHC setting are at significant risk of occupational exposure to BBF. However, most of these incidents were not reported mostly because of lack of time and perceptions that the incident BBF exposure was low risk. Furthermore, doctors and HCWs who were experienced and older were particularly at risk of not reporting these incidents.

Reporting BBF exposures has many values: firstly, it allows the affected HCW to receive appropriate and prompt medical assessment, counselling and treatment and post-exposure prophylaxis - activities that have been shown to reduce the

TABLE 1: Participants' characteristics.

\begin{tabular}{lcc}
\hline Characteristic & Frequency & $\%$ \\
\hline Gender & 391 & 88.1 \\
Female & 53 & 11.9 \\
Male & & \\
Age groups & 100 & 22.5 \\
$\leq 30$ years & 158 & 35.6 \\
$31-40$ years & 112 & 25.2 \\
$41-50$ years & 74 & 16.7 \\
$>50$ years & & \\
Occupation & 56 & 12.6 \\
Medical doctor/dentist & 69 & 15.5 \\
Enrolled nurse & 81 & 18.3 \\
Enrolled nurse assistant & 238 & 53.6 \\
Professional nurse & & \\
Work experience groups & 257 & 57.9 \\
$\leq 10$ years & 105 & 23.6 \\
11-20 years & 54 & 12.2 \\
21-30 years & 28 & 6.3 \\
$>$ 30 years & & 24.6 \\
Workplace & 92 & 54.7 \\
Clinic & 243 & \\
Community health centre & & \\
Hospital & & \\
\hline
\end{tabular}

risk of HIV seroconversion by as much as $79 \% .{ }^{11}$ Secondly, it enables the award of appropriate compensation as prescribed in the Compensation for Occupational Injuries and Diseases Act (COIDA) ${ }^{14}$ Lastly, by documenting exposures, it is possible to identify causes of BBF exposures and assess the effectiveness of preventive measures that have been put in place ensuring EBP. ${ }^{7}$

According to the literature, underreporting of BBF exposures is prevalent and may range between $22 \%$ and $82 \%$ of incidents. ${ }^{15,16,17,18}$ That $82 \%$ of BBF exposures in this study were not reported to a designated official has huge implications for the staff, their families and patients, and negates preventive efforts to minimise BBF exposures. Also, it makes the findings of root cause analysis of the documented exposures unreliable. This high underreporting rate contrasts the finding by Aigbodion et al. ${ }^{19}$ of an injury reporting rate of $98.9 \%$ among interns in Johannesburg. It is unclear whether this is because of a lower motivation to maintain health on the part of older HCWs or because of the phenomenon of desensitisation ${ }^{20}$ : the more an HCW is exposed to BBFs, the more relaxed they become with regard to reporting the exposures. The latter seems more plausible as it would explain our finding that doctors were significantly more likely to be exposed to, and less likely to report, BBF exposures than nurses.

The findings of this study confirm that lack of time ${ }^{21}$ is one of the most common reported reasons for underreporting of BBF exposures. This may be because of the following:

- The decentralisation and devolution of healthcare services in $\mathrm{SA}^{22}$ that has seen the PHC level of care take on more services and resulted in increased workload at PHC facilities. This, coupled with staff shortages and the pressure to push the queue, may cause HCWs to work

TABLE 3: Proportions of exposures reported and unreported.

\begin{tabular}{|c|c|c|c|c|c|}
\hline \multirow[t]{2}{*}{ Type of exposure } & \multicolumn{2}{|c|}{ Reported } & \multicolumn{2}{|c|}{ Not reported } & \multirow[t]{2}{*}{$p$} \\
\hline & $n$ & $\%$ & $n$ & $\%$ & \\
\hline Sharps & 50 & 31.4 & 109 & 68.6 & \multirow{2}{*}{$<0.001$} \\
\hline Non-sharps & 14 & 7.1 & 182 & 92.9 & \\
\hline Total & 64 & 18.0 & 291 & 82.0 & 355 \\
\hline
\end{tabular}

TABLE 4: Reporting patterns.

\begin{tabular}{lcc|}
\hline Participant characteristics & $\boldsymbol{n}$ & $\mathbf{\%}$ \\
\hline Number of participants exposed to blood and body fluids & 112 & 100.0 \\
Reported all exposures & 23 & 20.5 \\
Reported at least one of the exposures & 44 & 39.3 \\
Did not report any of the exposures & 68 & 60.7 \\
\hline
\end{tabular}

TABLE 2: Frequency of blood and body fluids exposures by professional category.

\begin{tabular}{|c|c|c|c|c|c|c|c|}
\hline \multirow[t]{2}{*}{ Profession } & \multicolumn{2}{|c|}{ Exposed } & \multicolumn{2}{|c|}{ Unexposed } & \multicolumn{2}{|c|}{ Total } & \multirow[t]{2}{*}{$p$} \\
\hline & $n(112)$ & $\%(25.2)$ & $n(332)$ & $\%(74.8)$ & $N(444)$ & $\%(100)$ & \\
\hline Doctors & 27 & 48.2 & 29 & 51.8 & 56 & 100.0 & - \\
\hline All nurses & 85 & 21.9 & 303 & 78.1 & 388 & 100.0 & $<0.001$ \\
\hline \multicolumn{8}{|l|}{ Exposure by nurse category } \\
\hline Enrolled nurses & 6 & 8.7 & 63 & 91.3 & 69 & 100.0 & $<0.001$ \\
\hline Enrolled nurse assistants & 12 & 14.8 & 69 & 85.2 & 81 & 100.0 & \\
\hline
\end{tabular}


faster and limit their attention to their own safety procedures. ${ }^{23}$ Overworked HCWs become less alert and more susceptible to BBF exposure ${ }^{24,25}$ and may not have time to report the incidents. This is evident in the high frequency of the reason of 'lack of time' among staff working at the clinics (55.0\%; Table 5).

- At the time of this study, PHC facilities did not have infection control or employee wellness officer, possibly increasing HCWs' reluctance to report incidents of BBF exposures. However, each BBF exposure is associated with risk of transmission of diseases (albeit small) if not well managed and this can be devastating for both the $\mathrm{HCW}$ and a healthcare system that is under-resourced in terms of human resources.

- Not all PHC clinics in SA have a resident doctor who can do an immediate assessment of staff with BBF exposure and even when present, most are not trained in occupational health assessment, management and administrative processes. The result is that HCWs are expected to report their BBF exposures to their immediate supervisor and then proceed to another facility for assessment and management. In addition, staff members often complain about the lengthy forms they must fill out and the time it takes to get the required signatures of designated officials. These lengthy processes take HCWs away from work for prolonged periods and have negative effects on staff morale, especially in facilities with barely adequate number of staff. The unfriendly processes may result in HCWs being reluctant to report their exposures and with poor management may increase the risk of acquiring and transmitting BBF infections to other patients and their loved ones.

TABLE 5: Reasons for not reporting exposures across settings and categories.

\begin{tabular}{|c|c|c|c|c|c|c|c|c|c|c|c|}
\hline \multirow[t]{2}{*}{ Reason } & \multirow[t]{2}{*}{ Frequency } & \multicolumn{2}{|c|}{ Clinic $(N=20)$} & \multicolumn{2}{|c|}{$\mathrm{CHC}(N=13)$} & \multicolumn{2}{|c|}{ Hospital $(N=56)$} & \multicolumn{2}{|c|}{ Doctor $(N=25)$} & \multicolumn{2}{|c|}{ Nurse $(N=64)$} \\
\hline & & $n$ & $\%$ & $n$ & $\%$ & $n$ & $\%$ & $n$ & $\%$ & $n$ & $\%$ \\
\hline I did not have time to report & 38 & 11 & 55.0 & 5 & 38.5 & 22 & 39.3 & 14 & 56.0 & 24 & 37.5 \\
\hline I did not know the reporting procedure & 14 & 1 & 5.0 & 0 & 0.0 & 13 & 23.2 & 4 & 16.0 & 10 & 15.6 \\
\hline I was concerned about confidentiality & 20 & 1 & 5.0 & 5 & 38.5 & 14 & 25.0 & 4 & 16.0 & 16 & 25.0 \\
\hline $\begin{array}{l}\text { I thought I might be blamed or get in trouble for } \\
\text { having the exposure }\end{array}$ & 11 & 6 & 30.0 & 2 & 15.4 & 3 & 5.4 & 0 & 0.0 & 11 & 17.2 \\
\hline I thought the source patient was low risk for HIV & 22 & 2 & 10.0 & 4 & 30.8 & 16 & 28.6 & 9 & 36.0 & 13 & 20.3 \\
\hline $\begin{array}{l}\text { I thought the source patient was low risk for hepatitis } \\
\text { B or C }\end{array}$ & 9 & 2 & 10.0 & 3 & 23.1 & 4 & 16.0 & 4 & 16.0 & 5 & 7.8 \\
\hline I thought the type of exposure was low risk for HIV & 19 & 6 & 30.0 & 4 & 30.8 & 8 & 32.0 & 8 & 32.0 & 11 & 17.2 \\
\hline $\begin{array}{l}\text { I thought the type of exposure was low risk for } \\
\text { hepatitis B or C }\end{array}$ & 9 & 3 & 15.0 & 3 & 23.1 & 4 & 16.0 & 4 & 16.0 & 5 & 7.8 \\
\hline I did not think it was important to report & 15 & 4 & 20.0 & 2 & 15.4 & 6 & 24.0 & 6 & 24.0 & 9 & 14.1 \\
\hline I did not want to know my HIV status & 1 & 0 & 0.0 & 0 & 0.0 & 1 & 1.8 & 0 & 0.0 & 1 & 1.6 \\
\hline $\begin{array}{l}\text { I did not want staff of this facility to know my HIV } \\
\text { status }\end{array}$ & 12 & 0 & 0.0 & 2 & 15.4 & 10 & 17.9 & 1 & 4.0 & 11 & 17.2 \\
\hline I already knew my HIV status & 5 & 1 & 5.0 & 1 & 7.7 & 3 & 5.4 & 0 & 0.0 & 5 & 7.8 \\
\hline
\end{tabular}

$\mathrm{CHC}$, commuinty health centre; HIV, human immunodeficiency virus.

TABLE 6. Association between participants' descriptors and the number of blood and body fluids reported.

\begin{tabular}{|c|c|c|c|c|c|c|}
\hline \multirow[t]{2}{*}{ Characteristics } & \multirow{2}{*}{$\begin{array}{c}\text { All exposures } \\
\quad N=355\end{array}$} & \multicolumn{2}{|c|}{ Exposures reported } & \multicolumn{2}{|c|}{ Exposures not reported } & \multirow[t]{2}{*}{$p$} \\
\hline & & $n$ & $\%$ & $n$ & $\%$ & \\
\hline \multicolumn{7}{|l|}{ Participant characteristics } \\
\hline Female & 251 & 48 & 19.1 & 203 & 80.9 & 0.40 \\
\hline Male & 104 & 16 & 15.4 & 88 & 84.6 & \\
\hline Age $\leq 50$ years & 298 & 60 & 20.1 & 238 & 79.9 & 0.02 \\
\hline Age $>50$ years & 57 & 4 & 7.0 & 53 & 93.0 & \\
\hline Doctor/dentist & 176 & 22 & 12.5 & 154 & 87.5 & 0.01 \\
\hline Nurse & 179 & 42 & 23.5 & 137 & 76.5 & \\
\hline$\leq 20$ years' work experience & 262 & 54 & 20.6 & 208 & 79.4 & 0.05 \\
\hline$>20$ years' work experience & 93 & 10 & 10.7 & 83 & 89.3 & \\
\hline \multicolumn{7}{|l|}{ Workplace and $\mathrm{OH} / \mathrm{EWP}$ training } \\
\hline Hospital based & 235 & 47 & 20.0 & 188 & 80.0 & 0.18 \\
\hline Non-hospital based & 120 & 17 & 14.1 & 103 & 85.9 & \\
\hline Others (night only and day and night) & 216 & 38 & 17.6 & 178 & 82.4 & \\
\hline Had training on infection control & 121 & 28 & 23.1 & 93 & 76.9 & 0.10 \\
\hline Did not have training on infection control & 234 & 36 & 15.4 & 198 & 84.6 & \\
\hline Had training on $\mathrm{OH} / \mathrm{EWP}$ & 81 & 17 & 21.0 & 64 & 79.0 & 0.53 \\
\hline Did not have training on $\mathrm{OH} / \mathrm{EWP}$ & 274 & 47 & 17.2 & 227 & 82.8 & \\
\hline Familiar with protocol & 260 & 47 & 18.1 & 213 & 81.9 & 0.37 \\
\hline Not familiar with protocol & 30 & 8 & 26.7 & 22 & 73.3 & \\
\hline
\end{tabular}

$\mathrm{OH}$, occupational health; EWP, employee wellness programme. 
Another common reason for not reporting BBF exposures is perceived low risk of infection transmission. ${ }^{26}$ This perception has been documented among HCWs across several clinical settings ${ }^{17,18,27}$ and represents a great deal of underestimation of risk of infection transmission following $\mathrm{BBF}$ exposure. While this study affirmed this, it raises serious clinical and public concerns, especially that SA is endemic for HIV and HBV (13.1\% and $4.3 \%$, respectively) $)^{28,29}$ and a significant proportion of the disease burden is now handled at the PHC level. Indeed, it may still be possible to transmit bloodborne infections even when the instrument is perceived sterile, for example, in a sharp instrument injury when the $\mathrm{HCW}$ is wearing blood-stained gloves. An elderly patient can no longer be considered a low HIV infection risk because of improved medication because HIV/AIDS patients are now living longer. All patients should always therefore be considered potential sources of bloodborne infection and standard universal precautions practised by all HCWs. Although our questionnaire was not designed to determine the circumstances of the respondent's BBF exposure, the literature is replete with evidence of risk underestimation by HCWs. ${ }^{19,25,30}$ Rapid reporting of needlesticks injuries and splashes leads to a substantial reduction in transmission of BBV infections..$^{31}$ It is imperative that every BBF exposure is reported to enable accurate estimates of the disease burden associated with occupational exposure to BBF and to ensure that EBP strategies are employed.

In this study, $22.5 \%$ of the participants did not report their BBF exposures because of concerns about confidentiality and $13.5 \%$ did not want other staff members in their facility to know their HIV status. This was more obvious among HCWs in the CHCs than hospitals $(38.5 \%$ and $15.4 \%$ vs. $25.0 \%$ and $17.9 \%$, respectively). This may be because staff complements in CHCs are usually smaller and members more closely knit than in the hospitals, making it more difficult to ensure confidentiality. Stigma and concerns about confidentiality have been cited in literature as reasons for underreporting of BBF exposure. . $^{32,33}$

More than $17 \%$ of nurses reported that they did not report exposures because they thought they might be blamed or get into trouble for having the exposure. The figures are higher among clinic staff members $(30.0 \%)$ whose productivity is mostly judged by the number of patients they attend to. They may be blamed for not adhering strictly to standard precautions or for being 'careless' and as exposure incidents increase in number, these may be used against them during performance evaluation. Thus, HCWs may not be reporting exposures because this would mean abandoning their work, which, in turn, affects their performance evaluation scores. This should not be so, as the socio-economic implications are grave for the HCWs, their dependents and even the employer if they seroconvert - prolonged time off work, expensive medical care and even medical boarding.

The reasons for failing to report a BBF exposure may be multifactorial and each factor could affect the complex explanation of this undesired behaviour. In the social-cognitive theory of behaviour, Bandura ${ }^{34}$ explains that behaviour, cognition and other personal factors and environmental influences all operate as interacting determinants that influence each other, albeit with different strengths. From this perspective, the final decision of reporting or not depends on the HCWs' perception of balance of the weights of the factors under the circumstanceif an exposure is perceived low risk but the HCW has plenty of time, he or she is more likely to report the incident than if time is limited. A high-risk exposure may not be reported by a staff member who does not have time or who is very worried about confidentiality. This reciprocal determinism implies that for a successful behavioural change by HCWs regarding exposure reporting, there is a need to recognise the environmental factors that may deter exposure reporting.

A complete overhaul of the implementation of the policy on accidental occupational exposure to BBF is therefore needed in South African PHC. This should align with the findings of Tabak et al. $^{35}$ that the best predictors of compliance to reporting of BBF exposures were the perceived efficiency of the reporting system, perceived severity of acquiring a disease and overall motivation to maintain health. The new system should include the establishment of a centralised, electronic injury reporting system coupled with a 24-h, dedicated local and provincial telephone hotline/helpline to handle BBF exposure reporting. This has been shown to improve reporting compliance significantly. ${ }^{36}$ Healthcare workers could call the helpline from anywhere at any time. The helpline should be linked to a network of personnel trained in injury reporting, counselling and clinical management. These personnel could be readily dispatched to the affected HCWs' facility to assist them with the necessary support. This will provide consistency and confidentiality and reassure and protect HCWs. It will eliminate the problem of lack of time and increase reporting rates.

There is no doubt that SA has rich experience in the establishment and management of 24-hour helpline as several of these lines are available in the country. However, at this time of economic stagnation and austerity, there is no doubt that budgeting and staffing of the helpline could pose some challenge. Funding for the establishment and running of the helpline could be sourced from the compensation fund. Collaboration between the departments of labour and health will be vital in the development of procedures and guidelines for using the helpline. There is a need to educate HCWs on the usefulness of the helpline for employee buy-in.

Continuous and targeted education of HCWs in the primary care setting on the risks of BBF exposures should be embarked on. This should include training aimed at changing HCWs' wrong perceptions about the risks of the source of BBF exposure. They should be educated on taking responsibility for their own health and safety and for that of others who may be affected by their actions at work. Awareness on suitability of HBV vaccination should be promoted. ${ }^{37}$ They must be educated on the need to evaluate their long-term risks in terms of possible seroconversion or infection rather than the short-term impact on their work. 
This could be incorporated into formal infection control training, including the use of universal standard precautions at the workplace which has been shown to improve reporting rate. ${ }^{38}$ Such education and training could be made mandatory for all staff by its inclusion in the performance management and development system.

\section{Summary}

Although BBF exposure rate in this South African PHC setting is high, most incidents were not reported. Reasons for the low rate of BBF exposure reporting include lack of time, low-risk perception of source of BBF and concerns about confidentiality. It is an urgent clinical and occupational health imperative to train $\mathrm{HCW}$ s on post-BBF exposure management policies, including preventive measures, objective risk assessment, the importance and mechanism of reporting and post-exposure drug treatment guidelines. ${ }^{17,24}$

\section{Limitations}

This study has some potential limitations: It relied on selfreports and is therefore susceptible to recall and information bias. However, BBF exposure is a significant event that is unlikely to be easily forgotten, especially that the period under consideration was limited to incidents that occurred in the last 12 months. The cross-sectional design precludes causal links, and attempts to generalise the findings need to take into account that this study was limited to only one district. Nonetheless, this study is one of few that have investigated exposure and reporting of BBF in South African primary care and highlights the need for interventions to promote reporting of every incident in this setting.

\section{Conclusion}

Accidental occupational exposure to BBF is common but under-reported in this typical South African PHC setting. Interventions aimed at addressing the low rate of reporting need to take cognisance of reasons such as lack of time, lack of confidentiality and low-risk perceptions. To upscale reporting, HCWs need to be trained on objective risk assessment, appropriate clinical response and prompt reporting procedures after BBF exposures. The establishment of a confidential 24-h central telephone hotline for reporting $\mathrm{BBF}$ exposures may facilitate reporting by eliminating some of the administrative barriers to reporting.

\section{Acknowledgements}

The authors acknowledge Dr Elizabeth Reji, who assisted with the development of the protocol.

\section{Competing interests}

The authors have declared that no competing interests exist.

\section{Authors' contributions}

All authors equally contributed to this work.

\section{Funding information}

This research received no specific grant from any funding agency in the public, commercial or not-for-profit sectors.

\section{Data availability statement}

Data sharing is not applicable to this article as no new data were created or analysed in this study.

\section{Disclaimer}

The views and opinions expressed in this article are those of the authors and do not necessarily reflect the official policy or position of any affiliated agency of the authors.

\section{References}

1. World Health Organization. The world health report 2002: Reducing risks, promoting healthy life [homepage on the Internet]. [cited 2012 May 15]. Available from: http://www.who.int/whr/2002/en/whr02_en.pdf

2. Auta A, Adewuyi EO, Tor-Anyiin A, et al. Global prevalence of percutaneous injuries among healthcare workers: A systematic review and meta-analysis. Int Epidemiol. 2018;47(6):1972-1980. https://doi.org/10.1093/ije/dyy208

3. Lachowicz R, Matthews PA. The pattern of sharps injury to healthcare workers at Witbank hospital. SA Fam Pract. 2009;51(2):148-151. https://doi.org/10.1080/20 786204.2009.10873831

4. Centers for Disease Control and Prevention. Workbook for designing, implementing, and evaluating a sharps Injury prevention program [homepage on the Internet]. [cited 2012 May 15]. Available from: www.cdc.gov/sharpssafety/ pdf/sharpsworkbook_2008.pdf

5. Pruss-Ustun A, Rapiti E, Hutin Y. Estimation of the global burden of disease attributable to contaminated sharps injuries among health-care workers. Am J Ind Med. 2005;48(6):482-490. https://doi.org/10.1002/ajim.20230

6. Rossouw TM, Van Rooyen M, Louw JM, Richter KL. Blood-borne infections in healthcare workers in South Africa. SAMJ. 2014;104(11):732-735. https://doi. org/10.7196/SAMJ.8518

7. Wilburn SQ, Ejikemans G. Preventing Needlestick injuries among health care workers: A WHO-ICN collaboration. Int J Occup Environ Health. 2004; 10(4):451-456. https://doi.org/10.1179/oeh.2004.10.4.451

8. Pruss-Ustun A, Rapiti E, Hutin Y. Sharps injuries: Global burden of disease from sharps injuries to health-care workers. WHO Environmental Burden of Disease Series, No. 3. Geneva: World Health Organization; 2003.

9. Wilburn SQ. Needlestick and sharps injury prevention. Online J Issues Nurs. 2004;9(3):5.

10. Zungu LI, Sengane ML, Setswe KG. Knowledge and experiences of needle prick injuries among nursing students at a university in Gauteng, South Africa. SA Fam Pract. 2008;50(5):48. https://doi.org/10.1080/20786204.2008.10873762

11. Karani H, Rangiah S, Ross AJ. Occupational exposure to blood-borne or body fluid pathogens among medical interns at Addington Hospital, Durban. S Afr Fam Pract 2011;53(5):462-466. https://doi.org/10.1080/20786204.2011.10874135

12. Karstaedt AS, Pantanowitz L. Occupational exposure of interns to blood in an area of high HIV seroprevalence. SAMJ. 2001;91(1):57-60.

13. Fullerton $M$, Gibbons V. Needlestick injuries in a healthcare setting in New Zealand. N Z Med J. 2011;124(1335):33-39.

14. Republic of South Africa. The Compensation for Occupational Injuries and Diseases Act, No 130 of 1993 (COIDA). Department of Labour, South Africa.

15. Tarantola A, Abiteboul D, Rachline A. Infection risks following accidental exposure to blood or body fluids in health care workers: A review of pathogens transmitted in published cases. Am J Infect Control. 2006;34(6):367-375. https://doi org/10.1016/j.ajic.2004.11.011

16. Schmid K, Schwager C, Drexler H. Needlestick injuries and other occupational exposures to body fluids amongst employees and medical students of a German university: Incidence and follow up. J Hosp Infect. 2007;65(2):124-130. https:// university: Incidence and follow up.
doi.org/10.1016/j.jhin.2006.10.002

17. Doebbeling BN, Vaughan TE, McCoy KD, et al. Percutaneous injury, blood exposure, and adherence to standard precautions: Are hospital based health care providers still at risk? Clin Infect Dis. 2003;37(8):1006-1013. https://doi. org/10.1086/377535

18. Awawu GN, Kabir S, Istifanus AJ. Occupational exposure to blood and body fluids among primary health-care workers in Kaduna State, Nigeria. J Med Trop. 2016;18(2):79-85. https://doi.org/10.4103/2276-7096.192223

19. Aigbodion SJ, Motara F, Laher AE. Occupational blood and body fluid exposures and human immunodeficiency virus post-exposure prophylaxis amongst intern doctors. S Afr J HIV Med. 2019;20(1):958. https://doi.org/10.4102/sajhivmed. v20i1.958

20. Makary MA, Attar AA, Holzmueller CG, et al. Needlestick injuries among surgeons in training. N Engl J Med. 2007;356(26):2693-2699. https://doi.org/10.1056/ NEJMoa070378 
21. Burke S, Madan I. Contamination incidents among doctors and midwives: Reasons for nonreporting and knowledge of risks. Occup Med. 1997;47(6):357-360. https://doi.org/10.1093/occmed/47.6.357

22. Hendricks SJH, Buch E, Seekoe E, Bossert T, Roberts M. Decentralisation in South Africa: Options for district health authorities in South Africa. SAHR. 2014/15;4:59-72.

23. Patrician PA, Pryor E, Fridman M, Loan L. Needlestick injuries among nursing staff: Association with shift-level staffing. Am J Infect Control. 2011;39(6):477-482. https://doi.org/10.1016/j.ajic.2010.10.017

24. Clarke SP, Sloane DM, Aiken LH. Effects of hospital staffing and organizational climate on needlestickinjuries to nurses. Am J Public Health. 2002;92(7):1115-1119. https://doi.org/10.2105/AJPH.92.7.1115

25. Auta A, Adewuyi EO, Tor-Anyiin A, et al. Healthcare workers' occupational exposures to body fluids in 21 countries in Africa: Systematic review and metaanalysis. Bull World Health Organ.2017;95(12):831-841F. https://doi.org/ 10.2471/BLT.17.195735

26. Haiduven DJ, Simpkins SM, Phillips ES, Stevens DA. A survey of percutaneous/ mucocutaneous injury reporting in a public teaching hospital. J Hosp Infect. 1999;41(2):151-154. https://doi.org/10.1016/S0195-6701(99)90053-1

27. Diprose P, Deakin CD, Smedley J. Ignorance of post exposure prophylaxis guidelines following HIV needle-stick injury may increase the risk of
seroconversion. $\mathrm{Br}$ J Anaesth. 2000;84(6):767-770. https://doi.org/10.1093/ seroconversion. $\mathrm{Br}$ J Anaest
oxfordjournals.bja.a013591

28. STATS SA. Statistical Release P0302 Mid-year population estimates 2018 [homepage on the Internet]. [cited 2018 Jan 21]. Available from: www.statssa. gov.za/publication/p0302/p0302218.pdf

29. Spearman CWN, Sonderup MW. Preventing hepatitis B and hepatocellular carcinoma in South Africa: The case for a birth-dose vaccine. S Afr Med J. 2014;104(9):610-612. https://doi.org/10.7196/SAMJ.8607
30. Patterson JM, Novak CB, Mackinnon SE, Patterson GA. Surgeons' concern and practices of protection against bloodborne pathogens. Ann Surg. 1998; 228(2):266-272. https://doi.org/10.1097/00000658-199808000-00017

31. Ebrahimi MH, Mirrezaie SM, Aghayan SS, et al. Occupational exposure to blood and other bodily fluids among laboratory technicians: An underestimated risk factor. Int J Health Stud. 2015;1(1):24-27.

32. Kerr HL, Stewart N, Pace A, Elsayed S. Sharps injury reporting amongst surgeons. Ann R Coll Surg Engl. 2009;91(5):430-432. https://doi.org/10.1308/00358840 9X432194

33. Yoshikawa T, Wada K, Lee JJ, et al. Incidence rate of needle-stick and sharps injuries in 67 Japanese hospitals: A national surveillance study. PLoS One [serial online] 2013[cited 2013 Nov 24];8(10):3. Available from: www.plosone.org

34. Bandura, A. Social cognitive theory. In: Vasta R, editor. Annals of child development. Vol. 6. Six theories of child development. Greenwich, CT: JAI Press, 1989; p. 1-60.

35. Tabak N, Shiaabana MA, Shasha S. The health beliefs of hospital staff and the reporting of needlestick injury. J Clin Nurs. 2006;15(10):1228-1239. https://doi. org/10.1111/j.1365-2702.2006.01423.x

36. HSE reporting guidance [homepage on the Internet]. [cited 2019 Sep 10]. Available from: http://www.hse.gov.uk/riddor/index.htm; http://www.hse.gov. uk/toolbox/managing/reporting.htm

37. Sali SH, Merza MA, Yadegarina D. Occupational exposure to blood borne viruses among healthcare workers in a tertiary care referral hospital in Tehran. Hepat Mon [serial online]. 2013[cited 2014 Jan 3];13(7):e12201. Available from: www.ncbi.nlm.nih.gov/pmc/articles/pmc3776233

38. Ersin F, Koruk ST, Yilmaz L. Effect of the training provided for nurses on sharp - Needlestick injuries and reporting process. Int J Caring Sci. 2016;9(2):561. 